\title{
Effects of the Horizontal Elements on Windward Wall of Buildings on Natural Ventilation and Pollutant Dispersion
}

\author{
Yuya Xiong and Hong Chen
}

\begin{abstract}
Natural ventilation is a well-known method to improve indoor air quality. Most studies did not consider the elements on building envelopes. This paper tries to investigate the horizontal elements' effect on one-sided ventilation of the windward rooms along a street canyon and study the dispersion of pollutant by using a computational fluid dynamic (CFD) model. Firstly, a three-dimensional numerical model for simulating flow and pollutant dispersion was developed by using the coded OpenFOAM and then validated against the water channel and the wind tunnel results. After the validation, four different widths of horizontal elements are applied to this present study, as well as a compared case, which is of no element $\left(W_{e}=0\right)$. Dimensionless pollutant concentration $\bar{C}$ and ventilation rates $(\mathrm{ACH})$ are analyzed. The numerical results reveal that the percentage decrease of average ventilation rate of buildings reaches $94.7 \%$ when the width of the horizontal elements $\left(W_{e}\right)$ is increased from $0.2 \mathrm{~m}$ to $1.5 \mathrm{~m}$. Besides, the pollutant concentration is reduced by adding the horizontal elements, though, the value of We do not influence the air flow. Elements on building envelope provides a possibility to improve the quality of building environment. This study intends to learn more about the effects of the horizontal elements on ventilation and pollutant dispersion and thus may contribute to city and building designs.
\end{abstract}

Index Terms - CFD simulation, OpenFOAM, ACH, pollutant concentration

\section{INTRODUCTION}

Natural ventilation is most well-known way to improve indoor air quality in China. However, with the increasing use of vehicles, as well as other environmental issues, the outdoor air pollution is severer and severer. Thus, natural ventilation may not improve the indoor air quality, but aggravate air pollution of the indoor environment.

Street and buildings are most important urban elements, where are the most important places of human activities. Field measurements, wind tunnel or water channel modeling, and computational fluid dynamics (CFD) simulations have been widely used to understand the pollutant dispersion and airflow patterns of the street canyon or the indoor environment. Studies by Chen et al. [1] and Zhao et al. [2] show that traffic emission is one of the major sources of air pollution in urban area. The street layout effects, such as building geometry, architecture and street canyon dimensions have been also widely studied. Oke et al. [3] has studied the flows and pollutant dispersion within a street, and summarized the flow regimes according to the ratio of the

Manuscript received February 15, 2019; revised August 23, 2019.

The authors are with School of Architecture and Urban Planning, Huazhong University of Science and Technology, Wuhan, Hubei, China (e-mail: cathaygrace@hust.edu.cn,Chhwh@hust.edu.cn). building height and the street width. Takano et al. [4] and Huang et al. [5] found that the shape of roof may influent the pollutant concentration inside the street canyon. Besides, a lot of investigators took attention to the indoor ventilation coupling with air flow in the urban street canyon. Yang et al. [6] investigated the wind flow and pollutant distributions in and around buildings with different window opening percentages (WOP) by three-dimensional numerical simulations. Among varied studies, however, the models of the street canyon or the buildings are always ignored the elements on the façade, including balconies, air conditioning equipment, shading elements. Aliabadi et al. [7] investigated the influence of roof-edge roughness elements on airflow, heat transfer and street-level pollution and found that the roof roughness element might improve thermal comfort and air quality in the canyon for specific times. Ai et al. [8] investigated the wind-induced single-sided natural ventilation in buildings of eight different envelopes near a long street canyon. They found that the envelope design could provide a possibility to enhance the adaptability of buildings to dense urban environments. However, there is no systematic study on the effects of horizontal elements on buildings envelope on the ventilation and pollutant dispersion in an urban street canyon.

This paper attempts to evaluate numerically the effects of horizontal elements on building envelopes on indoor ventilation and pollution concentration in the street canyon by using the CFD method. To start simply, we began with one idealized street canyon form, where the aspect ratio was 1.0. And buoyancy effects caused by solar radiation was not taken into account. Special attention is given to the effects of the horizontal elements with different widths.

\section{Methodology}

\section{A. CFD Model}

In this study, the numerical model for simulating air flow and pollutant concentration within urban street canyon and indoor building was established and solved by the open source CFD software OpenFOAM 5.0. The standard solver adapted was SimpleFoam, which was enable with a passive scalar transport model.

\section{1) Governing equations for airflow and pollution}

According to Huang et al. [5] and Wang et al. [9], the wind in both outdoor and indoor environments is numerically stable and could be regarded as incompressible turbulent flow. To simplify the simulation, the buoyancy effects due to solar radiation was not considered in this study. Considering the computational costs as well as accuracy, a most-commonly-used steady-state Reynolds-averaged 
Navier-Strokes (RANS) model, that is, the standard $\mathrm{k}-\varepsilon$ turbulence closure scheme was used to predict the flow and turbulence [10]. The pressure-velocity coupling algorithm was SIMPLE. The discretization scheme of all the variables except the pressure was bounded Gauss linearUpwind limited in OpenFOAM.

To simulate the pollutant release by vehicles, a line source $(0.3 \mathrm{~m} \times 75 \mathrm{~m} \times 0.3 \mathrm{~m})$ was set in the middle of the target canyon. Pollutant concentration was calculated by solution of time-averaged convection diffusion equation:

$$
\frac{\partial\left(u_{j} C\right)}{\partial x_{j}}=\frac{\partial}{\partial x_{j}}\left(K \frac{\partial C}{\partial x_{j}}\right)+Q_{e}
$$

where $C$ is the pollutant concentration. $\mathrm{K}$ is the turbulence diffusivity coefficient, and $K=D+v_{C} . D$ and $v_{C}$ are the molecular diffusivity and turbulent viscosity of pollutant $v_{C}=$ $v_{t} / S c_{t}, S c_{t}$ is the turbulent Schmidt number. $Q_{e}$ denotes the pollutant source term [6]. Since for air the Lewis number Le $=S c / P r \approx 1$, we can employ the concept of Reynolds analogy and assume $\mathrm{Sc}=P r$ and $S c_{t}=P r_{t}$ [11]. The laminar Prandtl number $(P r)$ for air is assumed to be 0.7 , and the turbulent Prandtl number $\left(P r_{t}\right)$ is taken to be 0.85 [7], [11].

\section{2) Computational domain and boundary conditions}

computational domain shown in Fig. 1(a) was chosen. Seven canyons were set in the domain, while the fifth canyon was the target canyon. The aspect $\operatorname{ratios}(\mathrm{H} / \mathrm{B})$ was 1.0 , namely, the height of buildings $(\mathrm{H})$ and the width of the street canyon(B) were both $15 \mathrm{~m}$. The upstream and downstream length of the domain were respectively $5 \mathrm{H}$ and $15 \mathrm{H}$. And the domain height above street canyon was $4 \mathrm{H}$. The width of domain $(\mathrm{L})$ is $5 \mathrm{H}$. The dimensions of one single room was $4 \mathrm{~m} \times 6 \mathrm{~m} \times 2.7 \mathrm{~m}$, which means there were 5 floors in the building. The rooms were placed at the middle of the target street canyon, shown in Fig. 1(b). In present study, one-sided natural ventilation, which is the most common natural ventilation mode, was considered. The windows, whose dimensions were $1.5 \mathrm{~m}$ in height and $1 \mathrm{~m}$ in width, were positioned $1 \mathrm{~m}$ above the floor in the middle of the walls, shown in Fig. 1(c). The width of the horizontal elements $\left(\mathrm{W}_{\mathrm{e}}\right)$ were varied from $0 \mathrm{~m}$ to $1.5 \mathrm{~m}$. And the thickness was identical $0.5 \mathrm{~m}$. The influence of the length of the element was ignored at present, so we assumed that the horizontal element was of infinite length. More details can be found in next section. To investigate the pollution by vehicles, we positioned a line source in the middle of the street, shown in Fig. 1(b). The dimensions of the emission line source were $0.5 \mathrm{~m} \times 75 \mathrm{~m} \times 0.3 \mathrm{~m}$

According to Z. T. Ai et al. [12] and X. Xie et al. [13], the

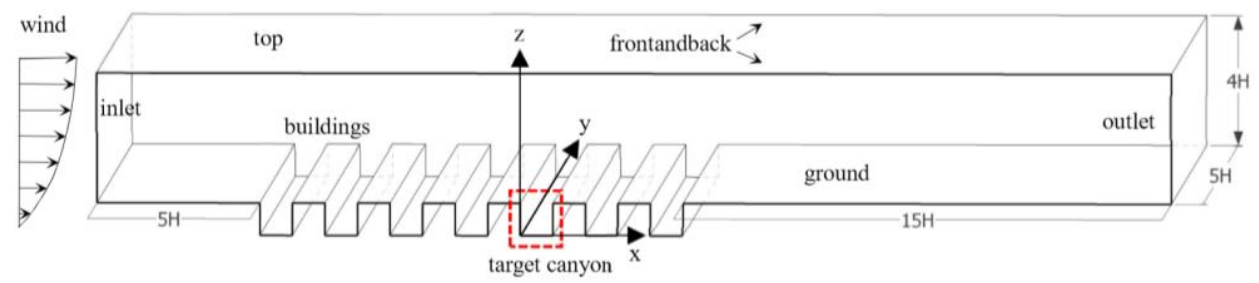

(a) Sketch of the computational domain
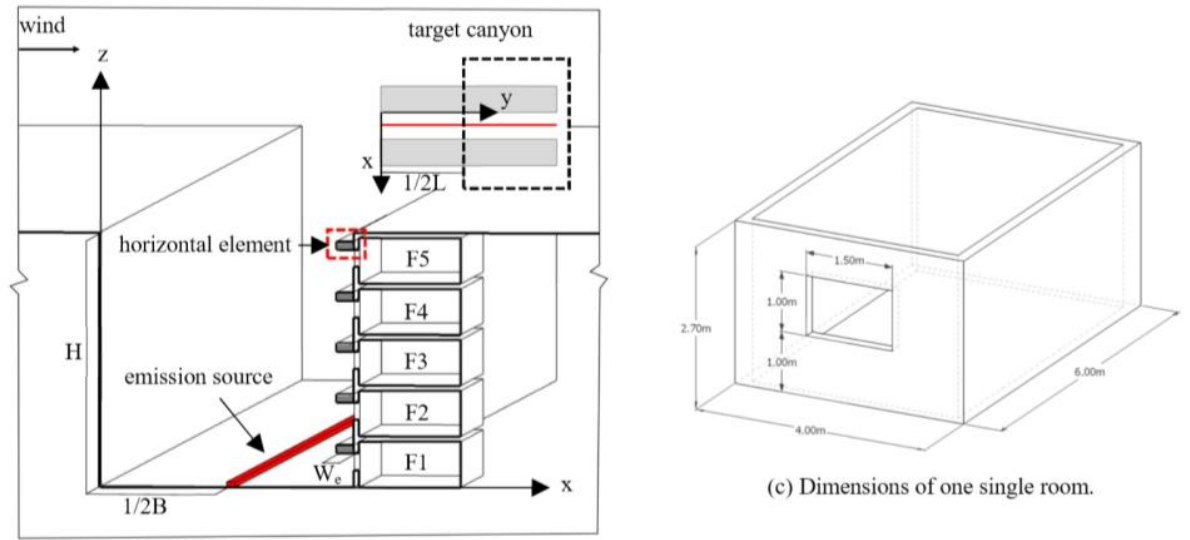

(c) Dimensions of one single room.

(b) Profile of the target street canyon.

Fig. 1. Setups of the computational domain and boundary conditions of the CFD.

Boundary conditions were chosen accordingly. The ground surface and building surfaces were considered smooth. No-slip conditions were applied to them. The top of the domain was symmetry, as well as front and back surfaces. This choice ensured that velocity and pressure gradients did not occur in the surface-normal direction. Table I gives the particular boundary conditions of the field variables. [14]

The wind profiles and the characteristics of turbulence were related to the terrain roughness of urban area. The direction of the wind was perpendicular to the street. The wind speed was given by power low formula shown in the following:

$$
\frac{u_{z}}{u_{r e f}}=\left(\frac{z}{H}\right)^{\alpha}
$$

where $u_{z}$ is the mean velocity at height of $\mathrm{z}(\mathrm{m} / \mathrm{s}) ; \alpha$ is the power law exponent dependent on the terrain roughness, in urban areas, the value is 0.25 [15], [6]. $\mathrm{H}$ is the reference 
height, i.e., the height of buildings; $u_{r e f}$ is the reference velocity at height of $\mathrm{H}$, which is $3 \mathrm{~m} / \mathrm{s}$ in this study.

Besides, the initial values of turbulent kinetic energy $(\mathrm{k})$ and dissipation rate $(\varepsilon)$ are shown in the following:

$$
\begin{aligned}
& k=\lambda\left(u_{z}\right)^{2} \\
& \varepsilon=C_{\mu}^{3 / 4} \frac{k^{3 / 2}}{\kappa z}
\end{aligned}
$$

where $\lambda$ is the turbulence intensity, $\lambda=0.03 . \kappa$ is the Von Karman constant, $\kappa=0.41$. And $C_{\mu}$ is an empirical constant, $C_{\mu}=0.09[16]$.
The pollution concentration is expressed in dimensionless for $\bar{C}$ as follows [6], [13]:

$$
\bar{C}=\frac{C_{i} H L U_{r e f}}{Q_{0}}
$$

where $C_{i}$ is the pollutant concentration at point $\mathrm{i}, \mathrm{kg} / \mathrm{m}^{3} ; Q_{0}$ is the pollutant emission rate per unit length, $\mathrm{kg} /(\mathrm{m} \cdot \mathrm{s}) . \mathrm{H}$ is the height of the buildings along the street, and $\mathrm{L}$ is the width of the street canyon. In OpenFOAM, we set the pollutant line source as scalarSemiImplicitSource by using the coded

\begin{tabular}{|c|c|c|c|c|c|c|}
\hline Physical quantity & $<\mathbf{u}_{\mathrm{i}}>$ & $<\mathbf{p}>$ & $\mathbf{k}$ & $\varepsilon$ & $v_{t}$ & $\mathrm{C}$ \\
\hline OpenFOAM variable & $\mathbf{U}$ & $\mathbf{p}$ & $\mathbf{k}$ & epsilon & nut & $\mathbf{C}$ \\
\hline inlet & groovyBC & zeroGradient & groovyBC & groovyBC & zeroGradient & fixedValue \\
\hline outlet & zeroGradient & fixedValue & zeroGradient & zeroGradient & zeroGradient & zeroGradient \\
\hline ground & fixedValue & zeroGradient & kqRWallFunction & epsilonWallFunction & nutWallFunction & zeroGradient \\
\hline buildings & fixedValue & zeroGradient & kqRWallFunction & epsilonWallFunction & nutWallFunction & slip \\
\hline top & symmetry & symmetry & symmetry & symmetry & symmetry & symmetry \\
\hline frontandback & symmetry & symmetry & symmetry & symmetry & symmetry & symmetry \\
\hline
\end{tabular}
fvOptions file.

TABLE I: BOUNDARY CONDITIONS OF THE FIELD VARIABLES IN OPENFOAM

\section{3) Case configuration}

To investigate the influences of the horizontal elements on building envelopes, we set 4 different widths, i.e., $0.2,0.5 \mathrm{~m}$, $1.0 \mathrm{~m}, 1.5 \mathrm{~m}$, as well as a compared case without the horizontal element. In present work, the thickness of the elements was not taken into consideration. The thickness of all cases was $0.5 \mathrm{~m}$. And the elements and rooms were applied on one side of the canyon in each case, that is, either the windward wall. To sum up, there are 5 cases, including one compare case.

\section{B. CFD Model Validation}

The water channel $\left(L_{S} \times W_{S} \times H_{S}=10 \mathrm{~m} \times 0.3 \mathrm{~m} \times 0.5 \mathrm{~m}\right)$ experiment by Li et al. [17], which is very similar to the simulation model of this study, was chosen for the validation of numerical simulation. The street canyons were formed by eight identical buildings models $\left(L_{B} \times W_{B} \times H_{B}=0.3 \mathrm{~m} \times\right.$ $0.1 \mathrm{~m} \times 0.1 \mathrm{~m}$ ). According to Li's experiment, the velocity of inlet flow was $1.8 \mathrm{~m} / \mathrm{s}$. The target canyon was located at located at the center. The experimental results data for aspect ratio $(\mathrm{AR})=1$ were used for validating the flow fields of our present simulate model. Besides, the results of a CFD simulation, using FLUENT 6.3.26 by F. Yang et al. [6], were also compared in this paper.

Stream-wise velocities $(u)$ and vertical velocities $(w)$ along the vertical probe-lines, which located at $\mathrm{x} / \mathrm{H}=0.25,0.5,0.75$ in the target canyon, were used to compare the numerical results and the experimental results. From Fig. 2, we can find observe that the current CFD simulation results, using OpenFOAM, are very familiar with the FLUENT ones. Fig. 2(a) - (c) shows that stream-wise velocities are in good agreement with the results of the water channel experiments, besides, the current CFD results are slightly closer to the experiment data. Fig. 2(d) - (f) shows that the vertical velocities are in good agreement with the experiment data except those of the center probe-line. But they are very familiar with the FLUENT results. And in this study, the near-wall flow, in another word, the probe-lines at $\mathrm{x} / \mathrm{H}=0.25$ and 0.75 are more important for predicting the ventilation. Nevertheless, the CFD model in this study can well simulate the flow fields in the street canyon.
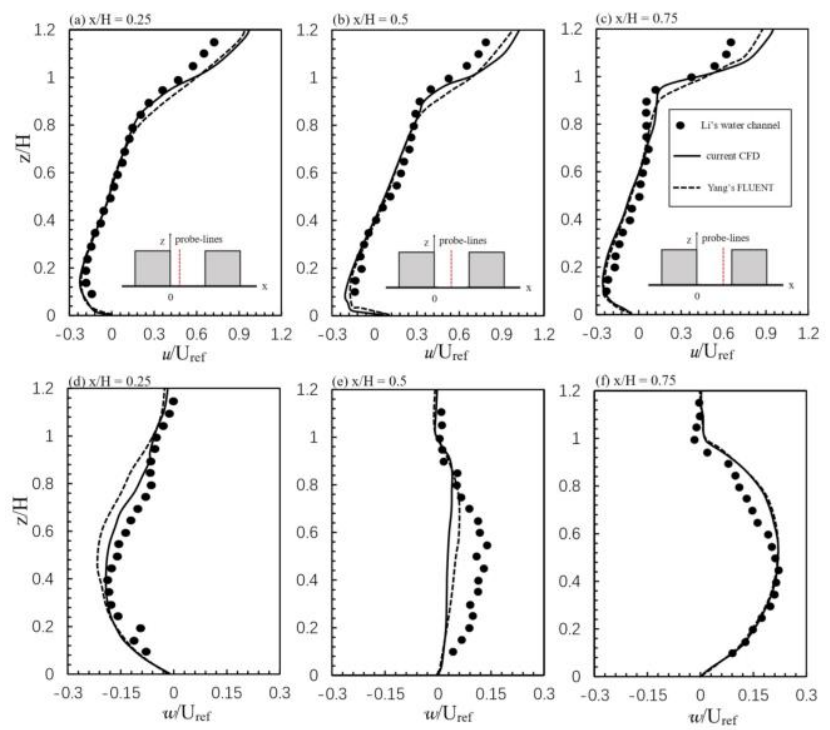

Fig. 2. Comparisons of simulated velocity components in $\mathrm{x}$ and $\mathrm{z}$ directions with Li's [7] water channel data and Yang's [6] FLUENT results.

To validate the concentration fields, the simulated results are compared with the wind tunnel measurements by Meroney et al. [18]. Also, the results of a CFD simulation, using FLUENT 6.3.26 by F. Yang et al. [6], is compared in 
this paper. In Meroney's study, the street canyon aspect ratio is 1.0 , which is equal to our study model. And a line source of ethane and air on the ground was located at the center of the street. the pollutant concentration is expressed by dimensionless $\bar{C}$, mentioned above. The experiment results for $U_{\text {ref }}=3.0 \mathrm{~m} / \mathrm{s}$, which is same with our study, is used to compared with our OpenFOAM's simulate results, shown in Fig. 3. The results show a greater satisfactory agreement with the wind tunnel experiment measurements than the FLUENT ones, especially on the leeward side.

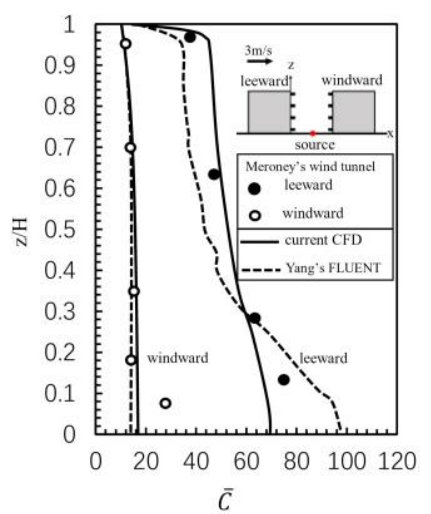

Fig. 3. Comparisons of simulated pollutant concentration with Meroney's experiment and Yang's FLUENT results.

Above all, the CFD model in this study can well simulate the flow fields and pollutant dispersion in the street canyon.

\section{RESULTS AND ANALYSIS}

We used the above verified CFD model to simulate the flow development inside the urban street canyon. In each simulation case, the boundary conditions are highly identical.

\section{A. Ventilation Fluxes and Pollutant Concentration}

In present study, since the length (in y direction) of the horizontal elements was not taken into consideration, we take $\mathrm{x}-\mathrm{z}$ plane as study plane, where $\mathrm{y}=37.5 \mathrm{~m}$ (right at the middle of the domain in y direction. Fig. 5 shows the dimensionless scalar velocity $\left(\bar{U} / U_{\text {ref }}=\sqrt{u^{2}+v^{2}+w^{2}} / 3\right)$ and streamlines on the middle $\mathrm{x}-\mathrm{z}$ plane of the target canyon. It can be observed that the velocity is reduced in the canyon, especially the bottom of the canyon, by adding the horizontal elements on the windward wall. Besides, when the horizontal elements placed, the position of the vortex in the canyon goes higher than the one without the elements. With the increasing width of the elements, there are small vortexes under the elements, which means the elements may obstruct the flow to enter the room.

Fig. 5 shows the dimensionless scalar velocity of leeward $(x / H=0.1)$ and windward $(x / H=0.9)$ wall, as well as the middle of the canyon $(x / H=0.5)$. We can find that there is a great difference between the cases with the horizontal elements and the case without the elements. As a whole, the horizontal elements can reduce the velocities in the street canyon. From Fig. 5(a), we can observe that the velocities are very close to each other, when with the horizontal elements. It tells that the width of the element $\left(\mathrm{W}_{\mathrm{e}}\right)$ is of little influence on the leeward flows. In the middle of the street canyon, shown in Fig. 5 (b), with increasing of $\mathrm{W}_{\mathrm{e}}$, the velocities reduce. When $\mathrm{W}_{\mathrm{e}}=1.0 \mathrm{~m}$ and $\mathrm{W}_{\mathrm{e}}=1.5 \mathrm{~m}$, the velocities are very similar. At the lower level of the street canyon, the velocities decreased by increasing width of the horizontal elements. On windward side, width of the horizontal elements plays a more important role in influencing the flow, as shown in Fig. 5 (c).
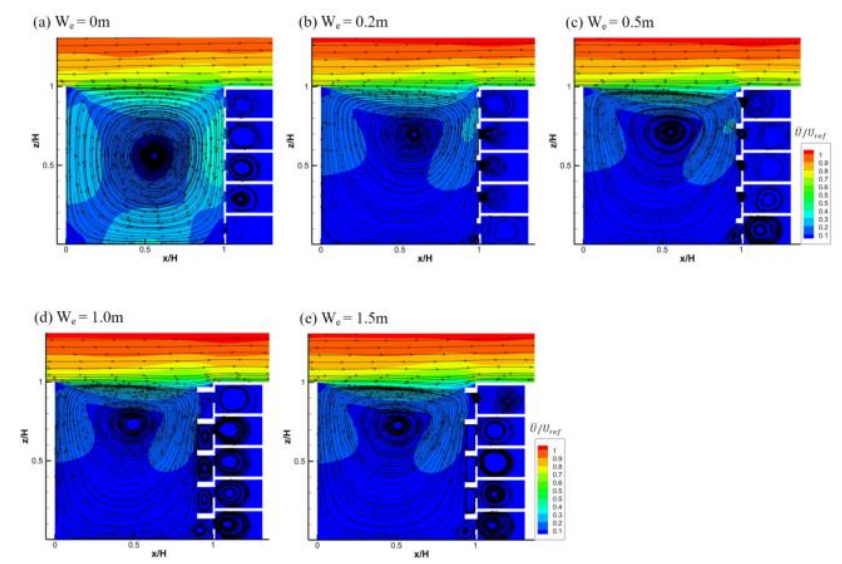

Fig. 4. The simulated scalar velocity $\left(\bar{U} / U_{\text {ref }}\right)$ contour and streamlines inside the target street canyon for various widths of the horizontal elements: (a) $W_{e}=0 \mathrm{~m}$; (b) $W_{e}=0.2 \mathrm{~m}$; (c) $W_{e}=0.5 \mathrm{~m}$; (d) $W_{e}=1.0 \mathrm{~m}$; (e) $W_{e}=1.5 \mathrm{~m}$. (a) $\mathrm{x} / \mathrm{H}=0.1$

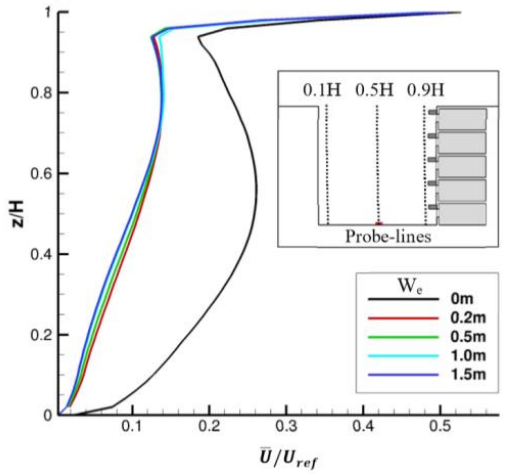

(b) $\mathrm{x} / \mathrm{H}=0.5$

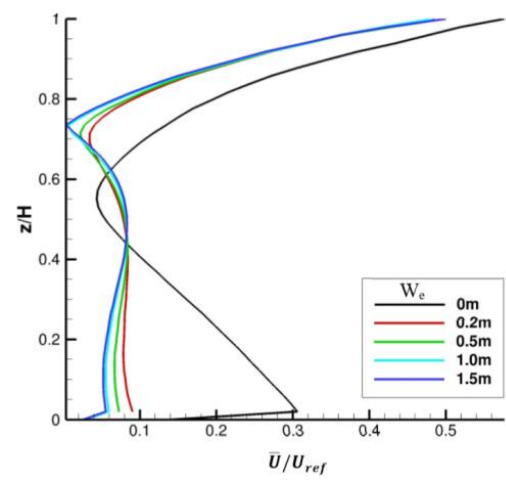

(c) $\mathrm{x} / \mathrm{H}=0.9$

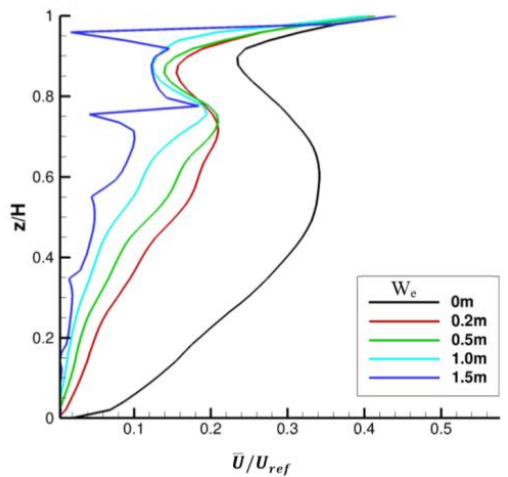

Fig. 5. The simulated dimensionless scalar velocity $\left(\bar{U} / U_{\text {ref }}\right)$ on different probe-lines: (a) $\mathrm{x} / \mathrm{H}=0.1$ (close to the leeward wall); (b) $\mathrm{x} / \mathrm{H}=0.5$ (in the middle of the street canyon); (c) $\mathrm{x} / \mathrm{H}=0.9$ (close to the windward wall).

Fig. 6 shows that the horizontal elements may reduce the pollutant dispersion into the buildings. The elements can provide the pollutant, which is emitted from the street, from the room. It may be due to the reducing of velocities in the 
street canyon. From Fig. 6 (b)-(e), the dimensionless the effects of the width are not obvious. pollutant concentration contour is very similar. In other word,

(a) $\mathrm{W}_{\mathrm{e}}=0 \mathrm{~m}$

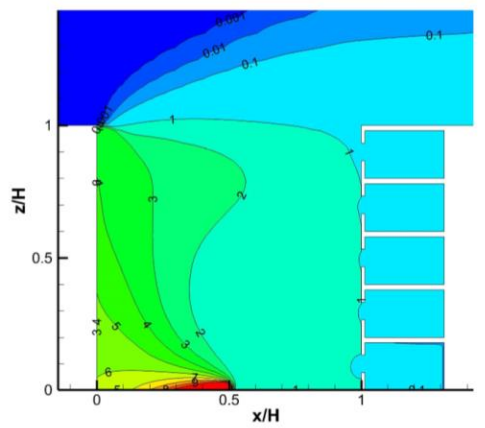

(b) $\mathrm{W}_{\mathrm{e}}=0.2 \mathrm{~m}$
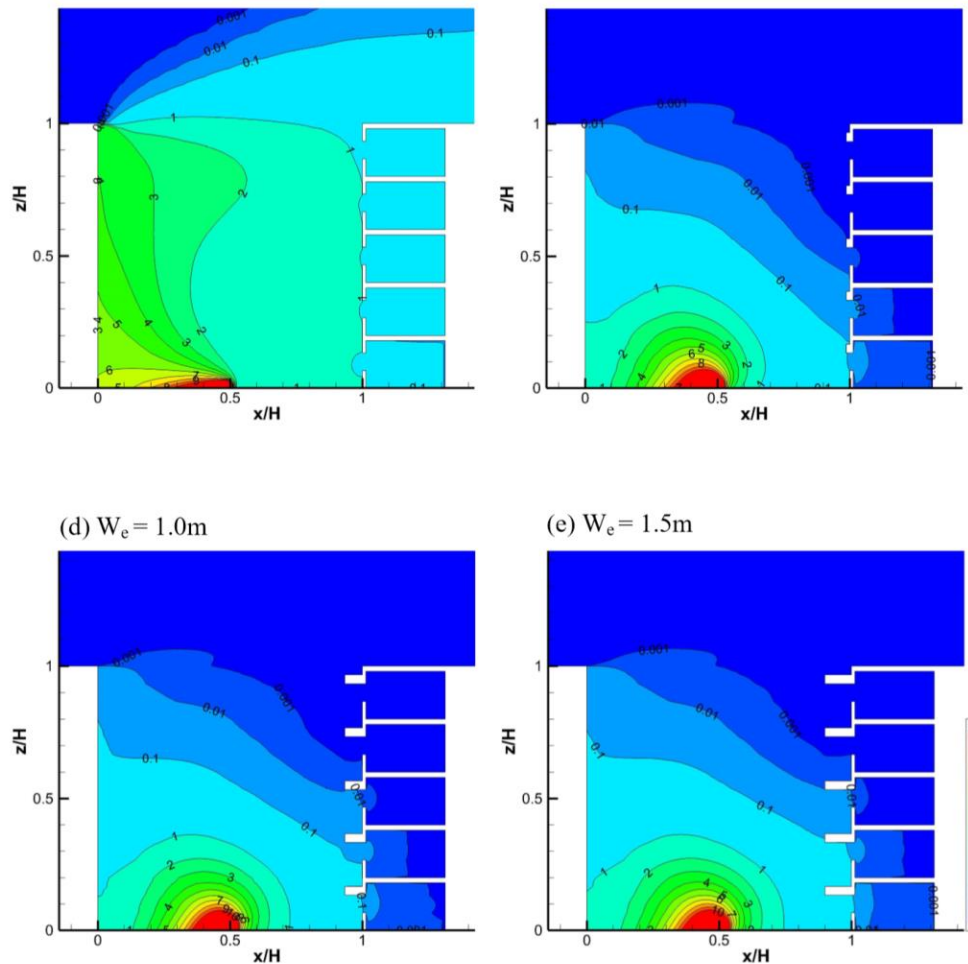

(e) $\mathrm{W}_{\mathrm{e}}=1.5 \mathrm{~m}$

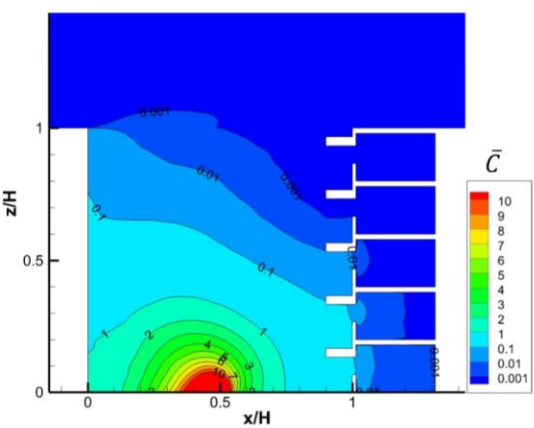

(c) $\mathrm{W}_{\mathrm{e}}=0.5 \mathrm{~m}$

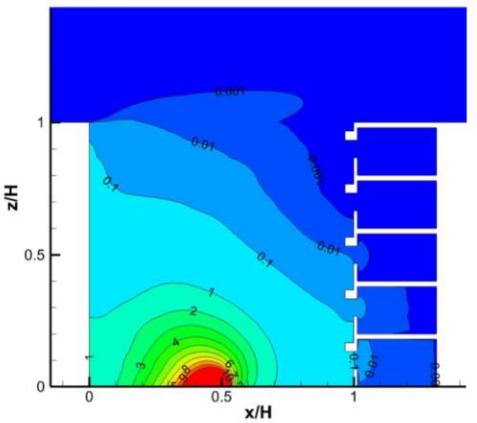

Fig. 6. The dimensionless pollutant concentration $(\bar{C})$ contour and streamlines inside the target street canyon for various widths of the horizontal elements: (a) $W_{e}=0 \mathrm{~m} ;$ (b) $W_{e}=0.2 \mathrm{~m} ;$ (c) $W_{e}=0.5 \mathrm{~m}$; (d) $W_{e}=1.0 \mathrm{~m} ;$ (e) $W_{e}=1.5 \mathrm{~m}$.
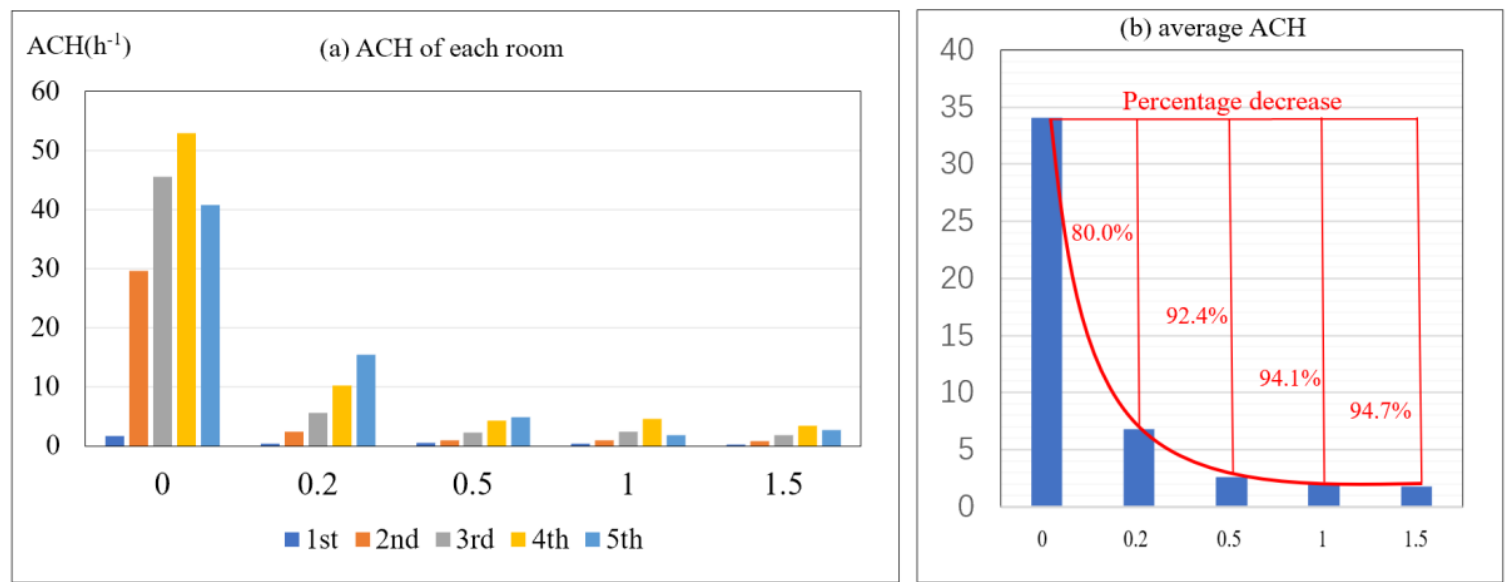

Fig. 7. The ACH values: (a) the ACH values of rooms in building under the different widths of the horizontal elements; (b) average ACH values of all 5 rooms under one width of the horizontal elements.

\section{B. Air Change Rate per Hour (ACH)}

The ventilation rate is an important parameter for evaluating natural ventilation of buildings. Calculation of the single-sided ventilation rate can be made based on either mean-velocity-based integral method or concentration-based tracer gas method [8], [19]. This study uses the integral method, which integrates the mean velocities on an opening that are extracted by the simulations: ${ }^{8}$

$$
Q_{\text {mean }}=\frac{1}{2} \sum_{m=1}^{M} \sum_{n=1}^{N}\left|U_{m, n}\right| \Delta y_{m} \Delta z_{n}
$$

where $Q_{\text {mean }}$ is the mean ventilation rate; $U_{m, n}$ is the mean velocity at a cell $(\mathrm{m}, \mathrm{n}) ; \Delta y_{m}$ and $\Delta z_{n}$ are the dimensions of the cell. The ACH can be expressed as follow:

$$
\mathrm{ACH}=Q_{\text {mean }} / V_{\text {room }}
$$

where $V_{\text {room }}$ is volume of a room. Here in this paper, the volume is $64.8 \mathrm{~m}^{3}$.

Fig. 7 (a) shows the $\mathrm{ACH}$ values of rooms in building under different widths of the horizontal elements. It is obvious that the $\mathrm{ACH}$ values along height are not always uniformly distributed. For $\mathrm{W}_{\mathrm{e}}=0,1$ and 1.5, the highest $\mathrm{ACH}$ values occur on the $4^{\text {th }}$ floor. Fig. 7 (b) shows the average $\mathrm{ACH}$ values of all 5 rooms under one width. And the average $\mathrm{ACH}$ values decrease with the increase of width of the horizontal elements. But with the increase of width, the decrease is tending to be gentle. For $\mathrm{We}=0.2$, the average 
$\mathrm{ACH}$ could decrease by $80 \%$. For $\mathrm{W}_{\mathrm{e}}=1.5$, the average $\mathrm{ACH}$ could decrease by $94.7 \%$.

\section{CONCLUSIONS AND DisCUSSION}

This paper tries to investigate the horizontal elements' effect on one-sided ventilation of the windward rooms along a street canyon, and study the dispersion of pollutant as well. Four different widths of horizontal elements are applied to this present study, as well as a compared case, which is of no element $\left(W_{e}=0\right)$. The CFD simulation results revealed that:

1) the horizontal elements on building envelopes could reduce the velocities near the windward wall. At the lower level of the street canyon, the velocities decreased by increasing width of the horizontal elements.

2) the horizontal elements can reduce the pollutant dispersion into the room. The width of the elements is of little influence on the pollutant dispersion, however.

3) Compared to the case of $W_{e}=0$, the percentage of average $\mathrm{ACH}$ values are $80 \%, 92.4 \%, 94.1 \%$ and 94.7\%. And the $\mathrm{ACH}$ values of each room along height of a building are not uniformly distributed.

As a primary work of our research, there are some limitations of the present study. First of all, this study investigates only the perpendicular wind direction even though it is the most widely used wind direction due to its association with the worst condition for ventilation and pollutant dispersion in a street canyon. ${ }^{8}$ More wind direction should be investigated. Secondly, the dimensions of the street canyon are simplified. And this study only considered AR=1. Different forms of street canyons should also be taken into account. Besides, buoyancy also effects the pollutant dispersion and air flows, but this study ignored it. For future work, the number of our configurations should be enlarged. More conditions will be investigated.

\section{CONFLICT OF INTEREST}

The authors declare no conflict of interest

\section{AUTHOR CONTRIBUTIONS}

Hong CHEN conducted the research. Yuya XIONG calculated and analyzed the data. All authors wrote this paper together and had approved the final version.

\section{REFERENCES}

[1] C. Chen, C. Huang, Q. Jing et al., "On-road emission characteristics of heavy-duty diesel vehicles in Shanghai," Atmospheric Environment, 2007, vol. 41, pp. 5334-5344.

[2] X. J. Zhao, P. S. Zhao, J. Xu et al., "Analysis of a winter regional haze event and its formation mechanism in the North China Plain," Atmos Chem Phys., 2013, vol. 13, pp. 5685-5696.

[3] T. R. Oke, "Street design and urban canopy layer climate," Energy and Building, 1998, vol. 11, pp. 103-113.
[4] Y. Takano and P. Moonen, "On the influence of roof shape on flow and dispersion in an urban street canyon," Journal of Wind Engineering and Industrial Aerodynamics, 2013, vol. 123, pp. 107-120.

[5] Y. D. Huang, W. R. He, and C. N. Kim, "Impacts of shape and height of upstream roof on airflow and pollutant dispersion inside an urban street canyon," Environmental Science and Pollution Research, 2015, vol. 22, pp. 2117-2137.

[6] F. Yang, Y. Kang, Y. Gao, and K. Zhong, "Numerical simulations of the effect of outdoor pollutants on indoor air quality of buildings next to a street canyon," Building and Environment, vol. 2015, vol. 87, pp. $10-22$.

[7] A. A. Aliabadi, E. S. Krayenhoff, and N. Nazarian, "Effects of roof-edge roughness on air temperature and pollutant concentration in urban canyons," Boundary-Layer Meteorology, 2017, vol. 164, pp. 249-279.

[8] Z. T. Ai and C. M. Mak, "Wind-induced single-sided natural ventilation in buildings near a long street canyon: CFD evaluation of street configuration and envelope design," Journal of Wind Engineering and Industrial Aerodynamics, 2018, vol. 172, pp. 96-106.

[9] Y. Wang, Y. Zhou J. Zhuo, and R. Rameezdeen, “A computational Fluid Dynamic (CFD) simulation of PM10 Dispersion caused by rail transit construction activity: A real urban street canyon model," Environmental Research and Public Health.

[10] X. X. Li and C. H. Liu, "Recent progress in CFD modelling of wind field and pollutant transport in street canyons," Atmospheric Environment, 2006, vol. 40, pp. 5640-5658.

[11] A. J. Reynolds, "The prediction of turbulent Prandtl and Schmidt numbers," Int J Heat Mass Transfer, vol. 18, no. 9, pp. 1055-1069, 1975.

[12] Z. T. Ai and C. M. Mak, "CFD simulation of flow in a long street canyon under a perpendicular wind direction: Evaluation of three computational settings," Building and Environment, 2017, vol. 114, pp. 293-306.

[13] X. Xie, Z. Huang, and J. Wang, "The impact of urban street layout on local atmospheric environment," Building and Environment, 2006, vol. 41, pp. 1352-1363.

[14] Y. Takono and P. Moonen, "On the influence of roof shape on flow and dispersion in an urban street canyon," Journal of Wind Engineering and Industrial Aerodynamics, 2013, vol. 123, pp. 107-120.

[15] J. O. P. Cheung and C. H. Liu, "CFD simulations of natural ventilation behavior in high-rise buildings in regular and staggered arrangements at various spacings," Energy Building, 2011, vol. 43, pp. 1149-58.

[16] H. K. Versteeg and W. Malalasekera, "An introduction to computational fluid dynamics: The finite volume method," Pearson Education Limited, ISBN 9780131274983.

[17] X. X. Li, D. Y. C. Leung, and C. H. Liu, "Physical modeling of flow field inside urban street canyons," Journal of Applied Meteorology and Climatology, 2018, vol. 47, pp. 2058-67.

[18] R. N. Meroney, M. Pavageau, S. Rafailidis, and M. Schatzmann, "Study of line source characteristics for 2-D physical modelling of pollutant dispersion in street canyons," Journal of Wind Engineering and Industrial Aerodynamics, 1996, vol. 62, pp. 37-56.

[19] Y. Jiang, D. Alexander, H. Jenkins, R. Arthur, and Q. Chen, "Natural ventilation in buildings: measurement in a wind tunnel and numerical simulation with large-eddy simulation," Journal of Wind Engineering and Industrial Aerodynamics, 2003, vol. 91, pp. 331-353.

Copyright $($ C 2019 by the authors. This is an open access article distributed under the Creative Commons Attribution License which permits unrestricted use, distribution, and reproduction in any medium, provided the original work is properly cited (CC BY 4.0).

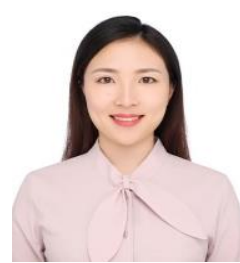

Yuya Xiong was born in 1989. From 2008 to 2013, she got the B.E. in architecture at School of Architecture and Urban Planning, Huazhong University of Science and Technology, Wuhan, Hubei, China.

From 2013-now, she is Ph.D. candidate at School of Architecture and Urban Planning, Huazhong University of Science and Technology, Wuhan, Hubei, China. Her research fields are green building design and green building technology. 